Birmingham Women's Health Care NHS Trust,

Birmingham

B15 2TG

Pallavi M Latthe specialist registrar

Khalid S Khan

consultant, education

resource centre

Tower Hill Medical

Centre, Birmingham

B42 1LJ

Manish Latthe general practitioner

Correspondence to:

K S Khan k.s.khan@

bham.ac.uk

Relation between credibility of website and accuracy of website's contents. Values are numbers (percentages) unless otherwise indicated

\begin{tabular}{|c|c|c|c|c|c|}
\hline \multirow[b]{2}{*}{ Feature of website credibility } & \multicolumn{3}{|c|}{ Levels of accuracy* } & \multicolumn{2}{|c|}{ Rank correlation } \\
\hline & $I$ & II & III & Kendall's tau b & $P$ value \\
\hline \multicolumn{6}{|l|}{ Description of source: } \\
\hline Present $(n=113)$ & $27(24)$ & $42(36)$ & $44(39)$ & 0.15 & 0.48 \\
\hline Absent $(n=8)$ & $1(12)$ & $1(12)$ & $6(76)$ & & \\
\hline \multicolumn{6}{|l|}{ Description of currency: } \\
\hline Present $(n=59)$ & $20(34)$ & $19(32)$ & $20(34)$ & 0.21 & 0.05 \\
\hline Present $(\mathrm{n}=22)$ & $7(32)$ & $10(45)$ & $5(23)$ & 0.16 & 0.25 \\
\hline Absent $(n=99)$ & $21(21)$ & $33(33)$ & $45(46)$ & & \\
\hline
\end{tabular}

*Level I: more than two thirds of guideline statements covered; level II: one third to two thirds of guideline statements covered; level III: less than one third of guideline statements covered.

website's contents and they were converted into three accuracy levels. In level I, more than two thirds of guideline statements were covered (28/121 (24\%) websites); in level II, one third to two thirds of guideline statements were covered (43 (35\%) websites); in level III, less than one third of guideline statements were covered (50 (41\%) websites).

We examined the relation between features of website credibility and level of accuracy of contents by cross tabulation and assessed the strength of association with Kendall's rank correlation, which adjusts for tied ranks in the data. The value of the coefficient (tau b) ranges from -1 to 1 . Interpretation is subjective, but values near zero may be taken to indicate no correlation whereas values near 1 indicate a strong correlation. As shown in the table, websites with description of credibility features tended to have higher levels of accuracy of contents, but this relationship was not strong.

\section{Comment}

Our study shows that features of website credibilitysource, currency, and evidence hierarchy-have only slight or at best moderate correlation with accuracy of information in five common health topics. Thus, apparently credible websites may not necessarily provide higher levels of accurate health information.

We thank Julie Morris for statistical input.

KSK conceived and designed the study. HK, DG, PML, ML and KSK searched, selected, and assessed websites. KSK and DG analysed and interpreted the data and wrote the manuscript. HK, PML, and ML revised the manuscript. KSK is guarantor for the paper.

Funding: None

Competing interests: None declared.

1 Silberg WM, Lundberg GD, Musacchio RA. Assessing, controlling, and assuring the quality of medical information on the internet. Caveant lector et viewor-let the reader and buyer beware JAMA 1997:977:1244-5.

2 Roberts JM, Copeland KL. Clinical websites are currently dangerous to health. Int J Med Inf 2001;62:181-7.

3 Kim P, Eng TR, Deering MJ, Maxfield A. Published criteria for evaluating health related websites: review. BMJ 1999;318:647-9.

4 Health Information Technology Institute. Criteria for assessing the quality of health information on the internet. http://hitiweb.mitretek.org/iq onlycriteria.html (accessed $15 \mathrm{Jan} 2002)$.

5 Griffiths KM, Christensen H. Quality of web based information on treatment of depression: cross sectional survey. BMJ 2000;321:1511-5.

(Accepted 4 February 2002)

\title{
Follow up of quality of public oriented health information on the world wide web: systematic re-evaluation
}

Chiara Pandolfini, Maurizio Bonati

In 1997 one of the first studies to evaluate the quality of health information on the internet was published. ${ }^{1}$ This article assessed the reliability of information for managing fever in children at home and found that the quality of information was poor. Four years after publication these findings were mentioned in 78 journals (from Journal Citation Report), and the message should therefore have reached a wide audience. We investigated the effects of the earlier findings by re-evaluating the quality of the original web pages four years later, as well as that of a more recent sample of pages, using the same methods.

\section{Methods and results}

On 28 June 2001 we searched articles through the Institute for Scientific Information's citation index for references to the earlier study. ${ }^{1}$ We searched for the 41 web pages evaluated in the original study to see if they still existed and if they did whether they had been substituted with new pages or their content had been modified. We compared the content with copies of the original pages, and we noted changes and assigned scores by using the guidelines and scoring system applied in the original study. ${ }^{1}$ We then repeated the 1997 search for new pages, found 40, and scored them as well. 
Completeness scores for original and new web pages in English. Values are numbers (percentages)

\begin{tabular}{lcccc}
$\begin{array}{l}\text { Completeness } \\
\text { score* }\end{array}$ & $\begin{array}{c}\mathbf{1 9 9 7} \\
(\mathbf{n}=\mathbf{3 8})\end{array}$ & $\begin{array}{c}\mathbf{2 0 0 1} \\
\mathbf{( n = 5 8 )}\end{array}$ & $\begin{array}{c}\text { Originals } \\
\text { remaining }(\mathbf{n}=\mathbf{1 8 )}\end{array}$ & $\begin{array}{c}\text { New entries } \\
(\mathbf{n}=\mathbf{4 0 )}\end{array}$ \\
\hline 0 & $1(3)$ & - & - & - \\
\hline 1 & $7(18)$ & $3(5)$ & $3(17)$ & - \\
\hline 2 & $7(18)$ & $9(16)$ & $3(17)$ & $6(15)$ \\
\hline 3 & $17(45)$ & $19(33)$ & $5(28)$ & $14(35)$ \\
\hline 5 & $3(8)$ & $23(40)$ & $5(28)$ & $18(45)$ \\
\hline
\end{tabular}

${ }^{\star} 0$, did not comply with guidelines for quality; 5 , complied with guidelines.

Overall, 19 of the $41(46 \%)$ original pages still existed. Of these, two had additional information leading, in one case, to a one point increase in completeness score. Five pages had been substituted with new content, leading to the score being increased in two of them ( 3 to 4 and 2 to 4 points). Three pages scored the same as the original pages $(2,3$, and 5 points). Only one of the four pages that had adhered completely to the guidelines ( 5 points) remained. Thus, the overall improvement in the pages' scores was only 4 points and was not significant with the Wilcoxon signed rank test.

To compare completeness scores, we made the old and new pages more homogeneous by considering pages in English only (table). The average score of the 38 original pages was 2.6 (SD 1.19), whereas that of the 40 new web pages was 3.4 (SD 0.81). The difference was significant $(\mathrm{P}<0.001)$ when measured with the MannWhitney U test.

Only two $(5 \%)$ of the new pages adhered to the guidelines for quality of content compared with three $(8 \%)$ of the original pages. However, $18(45 \%)$ of the new pages compared with only three $(8 \%)$ of the original pages adhered to most of the guidelines, except for one indication. All of the new pages concurred with paracetamol, dressing the child lightly, giving extra fluids, and when to call the doctor but 13 failed to specify that an antipyretic should be given before a sponge bath to lower the hypothalamic set point. Furthermore, none of the new pages suggested aspirin for children, whereas two of the original pages had (despite possible severe consequences).

\section{Comment}

The quality of health information on the internet has improved over the past few years despite concerns over poor quality and its possible consequences. ${ }^{2}$ The importance of low quality or incomplete information has led researchers to evaluate web pages in different disciplines and to define lists of requirements for users to evaluate the quality of web pages. ${ }^{3-5}$ Despite these apparently unproductive attempts to amend the situation, it has improved. Monitoring health information on the internet for accuracy, completeness, and consistency is still fundamental.

Contributors: CP was primarily responsible for data entry, management, and analysis; she will act as guarantor for the paper. MB guided the analyses. $\mathrm{CP}$ and $\mathrm{MB}$ contributed equally to writing the manuscript

Funding: None.

Competing interests: None declared.

1 Impicciatore P, Pandolfini C, Casella N, Bonati M. Reliability of health information for the public on the world wide web: systematic survey of advice on managing fever in children at home. BMJ 1997;314:1875-9.

2 Delamothe T. Quality of websites: kitemarking the west wind. BMJ 2000;321:843-4.

3 Pandolfini C, Impicciatore P, Bonati M. Parents on the web: risks for quality management of cough in children. Pediatrics 2000;105:e1.

4 Griffiths KM, Christensen H. Quality of web based information on treatment of depression: cross sectional survey. BMJ 2000;321:1511-5.

5 Risk A, Dzenowagis J. Review of internet health information quality initiatives. J Med Internet Res 2001;3(4):e28.

(Accepted 24 January 2002)

\section{A memorable patient}

\section{An escalating problem}

Mrs C, a 77 year old lady, was admitted to the Royal United Hospital Bath on 26 September after an usual sequence of events. Earlier that day she had been parking her automatic car, but when she stopped and got out to open her garage door she unfortunately failed to engage the handbrake. While she was opening the door, her car eased forward to knock her down and then roll over her right shoulder, trapping her underneath the vehicle. She cried out for help, and a friendly neighbour (Mrs Y) out walking with her 7 year old daughter (Miss Y) rushed to her aid. Mrs Y (not holding a UK driving licence) reluctantly got into the car and, with Mrs C's advice, engaged reverse, freeing Mrs C but unfortunately driving into her daughter and knocking her down. Hearing her daughter's cries, she drove forward, crashing the car into a wall.

All three were admitted to the accident and emergency department. Mrs C sustained an unstable fracture of the sixth and seventh cervical vertebrae and a floating $\mathrm{R}$ shoulder (glenoid and clavicle fractures).
The shoulder was treated conservatively, and she underwent operative stabilisation of her cervical spine. Miss $\mathrm{Y}$ was admitted under paediatricians and plastic surgeons with severe facial lacerations. Mrs Y was discharged home in a soft collar with a whiplash injury.

P K Das-Purkayastha, W F M Jackson senior house officers, department of orthopaedics, Royal United Hospital Bath

We welcome articles of up to 600 words on topics such as A memorable patient, A paper that changed my practice, My most unfortunate mistake, or any other piece conveying instruction, pathos, or humour. If possible the article should be supplied on a disk. Permission is needed from the patient or a relative if an identifiable patient is referred to. We also welcome contributions for "Endpieces," consisting of quotations of up to 80 words (but most are considerably shorter) from any source, ancient or modern, which have appealed to the reader. 